\title{
Lendo Utopias latino-americanas: política, sociedade e cultura: uma experiência de esperança em meio à distopia contemporânea
}

Flávio Vilas-Bôas Trovão ${ }^{1}$

PRADO, Maria Ligia. Utopias latino-americanas: políticas, sociedade e cultura. São Paulo: Contexto, 2021. 416p.

Resenha recebida em: 15/04/2021

Resenha aprovada para publicação em: 13/05/2021

A obra organizada por uma das maiores referências nos estudos de História da América Latina, a Prof ${ }^{a}$ Dra. Maria Ligia Prado, é a celebração de uma carreira exitosa e comprometida com a educação e a pesquisa histórica, que tem no continente americano seu objeto de investigação, afeto e também de militância.

Ainda que pareça desnecessária a apresentação de Maria Ligia Prado a muitos (as) estudiosos (as) de História das Américas, sua trajetória merece destaque, sobretudo no contexto de lançamento do livro em tela: a comemoração do seu octogésimo aniversário. Prado desenvolveu os seus estudos de graduação, mestrado e doutorado na Universidade de São Paulo (USP) e ali atuou como professora e pesquisadora por mais de quatro décadas. Sua dedicação pode ser medida pela dimensão da sua produção intelectual - foram dezenas de artigos científicos, capítulos de livros, organização e autoria de livros e obras coletivas (como essa), entre outras dezenas de produções bibliográficas e técnicas.

As atividades acadêmicas ultrapassaram fronteiras. Proferiu palestras em várias Universidades latino-americanas e, entre 1987 e 1995, ministrou oito cursos em centros de excelência acadêmica nos Estados Unidos: Universidades de Brown, Stanford e Nova York. Entre 2007 e 2010, Maria Ligia Prado coordenou o projeto temático

\footnotetext{
1 Doutor em História Social (USP), Professor do Curso de História da Universidade Federal de Rondonópolis (UFR), onde desenvolve pesquisas sobre História dos Estados e Cinema; Cinema, Educação e Ensino de História. flavio.trovao@ufr.edu.br
} 
"Cultura e política nas Américas: circulação de ideias e configuração de identidades séculos XIX e XX”, financiado pela FAPESP, que reuniu pesquisadores (as) vinculados (as) à USP, UNESP, UNICAMP, UNIFESP, UEL e UFMG, experiência que marcou o percurso acadêmico e profissional de professores (as) e pós-graduandos (as) envolvidos.

Como professora de graduação no curso de História, Maria Ligia Prado destacou-se, além da originalidade de suas aulas (bastante concorridas entre os estudantes), como uma promotora da pesquisa entre os iniciantes do ofício de historiador, tendo orientado dezenas de estudantes em projetos de iniciação científica.

Sua atuação na pós-graduação no Programa de História Social da USP, em parceria com Maria Helena Capelato (amigas há 50 anos), estabeleceu em definitivo a área de História das Américas enquanto campo de pesquisa. Orientou dezenas de trabalhos de Mestrado e Doutorado, supervisionou outros de pós-doutorado, formando gerações de historiadores (as) americanistas que hoje atuam como formadores (as) das novas gerações, em diferentes centros de conhecimento do Brasil. Esteve presente, também, em mais de uma centena de bancas de arguição de mestrado e doutorado no Brasil e outros países latino-americanos, como México e Argentina.

Em outra importante parceria com Capelato e outros (as) historiadores (as), Prado fundou a Associação Nacional de Pesquisadores (as) e Professores (as) de História das Américas (ANPHLAC), em 1982, da qual foi também presidenta (19982000), e o Laboratório de Estudos de História das Américas (LEHA), do Departamento de História, em 2011. Como reconhecimento pelas contribuições e pela rica trajetória, a comunidade acadêmica da Universidade de São Paulo lhe outorgou o título de Professora Emérita, no ano de 2012.

O livro "Utopias latino-americanas: políticas, sociedade e cultura" é um marco celebrativo pelo aniversário e pela trajetória de Maria Ligia Prado. Como afirma Maria Elisa Noronha de Sá, que assina as capas internas do livro,

(...) é um presente com que nos brinda sua idealizadora, Maria Ligia Prado. Ao completar 80 anos, ela, pioneira e mestra maior de todos que trabalham com a História da América Latina no Brasil, é quem merecia ser presenteada, mas seguindo sua habitual generosidade, decide ser esta a melhor maneira de ser homenageada. 
É por essa razão que os co-autores (as) e autores (as) dos 22 artigos que compõem o livro são oriundos, não integralmente, mas em grande parte, do trabalho de orientação ou parcerias de Prado junto ao Programa de Pós-Graduação em História Social, do Departamento de História da USP.

Dividido em cinco grandes blocos, articulados sempre em torno de alguma perspectiva utópica vivida historicamente no continente latino-americano, o livro aborda uma diversificada gama de temas, personagens, temporalidades e culturas latinoamericanas, frutos da renovação historiográfica da História Social, da História Política Renovada, da Nova História Cultural e também da História das Mulheres e de Gênero. Tarefa difícil é tentar definir qual dessas perspectivas é a mais cara à idealizadora da obra. O fato é que o trânsito historiográfico que Prado realizou ao longo de sua carreira se faz sentir, igualmente, nas produções que compõem a obra.

Utopia é, ao mesmo tempo, tema e conceito com centralidade no livro, além de elo que articula as diferentes histórias narradas ao longo dos textos. Em prefácio assinado por Fabiana de Souza Frederigo (UFG), o leitor é lembrado de que tal conceito pode ser interpretado por diferentes matrizes epistemológicas, mas aqui é tomada como experiência histórica, política, social e cultural. Dessa forma, acreditamos que a obra acaba por apontar experiências e possibilidades históricas a um país cansado e atônito diante de mais de 400 mil mortos pela pandemia de COVID-19. Para Frederigo, "exatamente porque vivenciamos tempos distópicos, voltamo-nos ao exame das utopias." (PRADO, 2021, p. 12).

O primeiro bloco de textos, intitulado "Utopias étnico-raciais e de gênero", inicia-se com a produção de Maria Ligia Prado e Romilda Costa Motta. Nesse ensaio, as autoras resgatam a história de mulheres latino-americanas que não se subordinaram ao "destino histórico" que lhes fora conferido, fosse no século XIX ou no XX, tempos vividos pelas personagens escolhidas para reflexão. A Utopia aparece, assim, encarnada no corpo e na trajetória de mulheres que conseguiram vencer barreiras como o machismo e a perseguição política, transformando a condição feminina, de lugar de subalternidade, em instrumento político de luta e resistência. Dessa forma, superaram os desafios de seus tempos, abrindo possibilidades para uma sociedade mais justa e democrática. 
Os demais textos que compõem o bloco, de autorias de Stella Maris Scatena Franco (USP), Gabriel Passetti (UFF), Tania da Costa Garcia (UNESP) e Flávio Thales Ribeiro Francisco (UFABC) passam por histórias de lugares como Cuba, Argentina, Colômbia e, claro, o Brasil, compreendido como mais uma nação na qual os grandes temas latino-americanos estão conectados. A escolha pela abertura do livro com textos que privilegiam abordagens historiográficas a partir da perspectiva étnico-racial e de gênero, como as resistências indígenas, as articulações políticas e culturais de movimentos negros e a escrita feminina, parecem apontar para a política vivida no Brasil nas últimas décadas, como avanços e resistências desses sujeitos sociais.

A seção seguinte se intitula "Utopias do conhecimento" e conta com outro texto de Maria Ligia Prado, agora em co-autoria com Valdir Santos (IFSP). O artigo acompanha o processo de implantação de uma política nacional de educação pública e laica na Colômbia, em meados do século XIX, e seus embates. Mais uma vez, o texto de abertura parece dialogar diretamente com a realidade que se vivencia no presente brasileiro e, também, em outros países latino-americanos, diante das tentativas de retrocessos de caráter neoconservador e base confessional vividas no campo da educação pública.

Os demais textos são de autorias de Gabriella Pelegrino Soares (USP), Marta de Almeida (UNIRIO) e Marcos Cueto (FIOCRUZ) e traçam um quadro da produção de conhecimento científico na América Latina na virada dos séculos XIX e XX. Entre esses campos epistemológicos, ganham destaque a arqueologia, antropologia e a etnografia na América Central, além do México e o Peru e a constituição de políticas sanitárias com vistas ao combate às chamadas doenças tropicais, que afligiam o continente naquela virada de século. Mais uma vez o Brasil ganha aqui destaque, agora com a personagem de Carlos Chagas e sua participação no contexto histórico-sanitário continental da época. Fecha o bloco o texto de Camilo de Mello Vasconcellos (USP) e William Alfonso López Rosas (Universidade Nacional da Colômbia), que historicizam o processo de constituição do "Museu Itinerante de Memória e Identidade de Montes Maria”, na Colômbia, em uma experiência de construção do saber a partir da organização coletiva e política de intelectuais, jornalistas, camponeses e jovens. Se no início dessa seção a preocupação por uma educação pública ameaçada no passado (e no 
presente) problematiza as utopias do conhecimento no continente latino-americano, em seu final, a história de $\mathrm{O}$ Mochuelo, o museu itinerante colombiano analisado por Vasconcellos e Rosas, renova os horizontes de expectativas e sustenta a utopia da construção coletiva e democrática do conhecimento e das políticas culturais nas Américas.

O terceiro bloco intitula-se "Utopias, representações e imaginários" e conta com textos escritos por Barbara Weinstein (New York University), Patrícia Funes (Universidad de Buenos Aires), Júlio Pimentel Pinto (USP) e Carlos Alberto Sampaio Barbosa (UNESP). Os conceitos de representação e imaginário, caros aos historiadores, são articulados a partir da análise de fontes como textos jornalísticos, literários, linguísticos e fotográficos. Weinstein analisa a trajetória de Frank Tannenbaum, historiador norte-americano que, contemporâneo aos fatos da Revolução Mexicana, postulava uma aproximação dos Estados Unidos ao vizinho do sul, não numa perspectiva de dominação e controle, mas, ao contrário, percebendo nas experiências históricas vividas pelos mexicanos, exemplos para o desenvolvimento dos Estados Unidos. Patricia Funes analisa a utopia de união latino-americana por meio da língua, a partir dos trabalhos do escritor dominicano Pedro Henriquez Ureña e do pintor argentino Xul Solar. Esses intelectuais integravam uma espécie de vanguarda linguística e artística nos anos 1920, apontando para uma renovação epistemológica pretendida naquela época. Júlio Pimentel Pinto analisa "Os diários de Emilio Renzi”, procurando identificar os momentos em que a América Latina aparece nos relatos autobriográficos do escritos argentino Ricardo Piglia, destacando as representações do continente para além de seus conflituosos episódios durante a Guerra Fria.

Esse conjunto de escritos é encerrado com a análise dos trabalhos fotográficos de Sebastião Salgado e Enrique Bostelmann, por Carlos Alberto Sampaio Barbosa. Destacando a potência e a força política que as imagens criadas pelos dois importantes fotógrafos latino-americanos desempenharam na construção de um olhar utópico, assim como podem ser lidos enquanto instrumentos de denúncia das violências e injustiças que marcam a desigualdade social, tanto no Brasil dos anos 1980, quanto no México dos anos 1970. 
O próximo grupo de artigos se dedica à análise das "Utopias Políticas". Isso não significa que os demais textos da coletânea não carreguem essa perspectiva, mas nesse conjunto de artigos o tema da política institucional ganha o foco. O bloco é aberto com o trabalho de Maria Helena Capelato (USP) analisando o governo de Salvador Allende no Chile e a experiência democrática socialista que se tentou implantar naquele país, mas que teve como trágico fim a morte do presidente, em um ataque à sede do governo, e a instauração de uma ditadura militar. Ao apontar que talvez "a dinâmica da desunião das esquerdas contribuiu para a derrota final do governo Allende" (PRADO, 2021, p. 254), Capelato nos permite pensar a política brasileira atual e os rumos futuros que deverão ser tomados no Brasil, em especial pelas forças políticas progressistas.

Na sequência, o texto de Luiz Felipe Viel Moreira (UEM) aborda a questão das políticas neoliberais na América Central (El Salvador, Nicarágua e Costa Rica), articulando o pensamento histórico, pautado em dados e políticas econômicas, com a literatura como fonte. Tereza Maria Spyer Dulci (UNILA) demonstra, em seu artigo, como no Equador e na Bolívia o conceito de "bem viver", originário de grupos indígenas, possibilitou a articulação de movimentos sociais de base étnica em mobilizações políticas, com vias às mudanças nos processos constitucionais, na história recente desses países. Encerra esse conjunto o ensaio jornalístico de Sylvia Colombo (Folha de São Paulo), analisando os avanços e contradições dos governos de Hugo Chávez e Nicolas Maduro, na Venezuela, a partir do olhar pessoal de quem acompanhou os eventos históricos in loco, como correspondente do jornal Folha de São Paulo para a América Latina. Nesse sentido, a esperança que a subida de Chávez ao poder representou para o subcontinente, enquanto líder progressista, acabou ofuscada pelos atos do governo Maduro, que apontam em uma direção centralizadora e pouco democrática.

Se o conjunto de textos que discutiu as utopias políticas coloca o leitor diante da dura realidade dos fatos históricos e, por vezes, da crise das utopias progressistas no continente, o quinto e último bloco retoma uma das utopias mais marcantes na História da América Latina: as "Utopias da integração e da identidade latino-americana".

O texto de abertura, escrito por Mary Anne Junqueira (USP), analisa as articulações entre as tentativas de implantação de uma política pan-americanista no 
continente, encabeçada pelos Estados Unidos, e suas resistências e adesões pelos demais países do continente, no final do século XIX e início do século XX. Em uma perspectiva do historiador das Relações Internacionais, Junqueira apresenta ao leitor os meandros da política internacional nas Américas, em um momento histórico de disputas e consolidação das nações, demonstrando que não houve uma posição única em relação às propostas diplomáticas e ações econômicas dos Estados Unidos na época.

Na sequência, o texto de Kátia Gerab Baggio (UFMG) dá continuidade ao tema da integração latino-americana, agora pelo olhar do intelectual argentino Manuel Ugarte, um defensor da integração do continente, porém, grande crítico do chamado imperialismo norte-americano. A partir da trajetória pública de Ugarte, vemos como o sentimento de latinidade e anti-americanismo foram disseminados em vários países do continente por meio da sua ação intelectual. O penúltimo texto da coletânea, assinado por José Luis Beired (UNESP), continua a desenvolver o tema da integração latinoamericana, analisando trajetórias intelectuais vinculadas ao Centro Brasileiro de Análise e Planejamento (Cebrap), nos anos 1970, no Brasil, que congregou intelectuais como Fernando Henrique Cardoso e Celso Furtado na construção de um pensamento sociológico e econômico sobre a região e suas possíveis vias de desenvolvimento.

Encerra a coletânea o artigo de Regina Ainda Crespo (UNAM - México), problematizando as últimas articulações políticas de integração sul-americana assinadas pelo Brasil, tomando os organismos da UNASUL, criado durante os governos progressistas e de centro-esquerda e esquerda que governaram recentemente o continente, e o PROSUL, foro que representa os interesses da nova e atual direita sulamericanas. Cada uma dessas instituições representam projetos diametralmente opostos: o primeiro integracionista (multilateral), o segundo isolacionista (bilateral) e alinhado, em grande parte, aos interesses norte-americanos.

A integração latino-americana continua sendo uma utopia, talvez a maior a ser perseguida e construída no continente, desde a época de Simon Bolívar e José Martí, passando por tantas outras que permeiam os textos dessa coletânea. Ao final da leitura do livro um sentimento de esperança e comprometimento político e social se faz sentir. Seja enquanto historiadores, comprometidos com a escrita de outras histórias possíveis para os povos e grupos latino-americanos, seja enquanto cidadãos brasileiros, ao rever 
as trajetórias do país em relação aos seus vizinhos e às utopias que podem ser (re)construídas, a fim de superar a distopia e o medo que nos trouxeram até aqui.

Como nos lembram Maria Ligia Prado e Valdir Santos,

A despeito desse quadro tão assustador, é importante nunca se esquecer, como nos ensinou Karl Mannheim, de que é a capacidade de acalentarmos as utopias que nos torna humanos. Apesar dos pesares, é importante que sigamos utópicos, pois só assim continuaremos reconhecendo nossa própria humanidade, resistindo a disparates que, infelizmente, têm sido cotidianos e acreditando que uma outra sociedade ainda é possível. (PRADO, 2021, p. 125) 